\title{
Proportional reasoning: Reducing the interference of natural numbers through an intervention based on the problem-solving framework of executive functions
}

\author{
Reuven Babai ${ }^{1,2^{\star}}$, Eldad Cohen ${ }^{1}$, Ruth Stavy ${ }^{1,2}$
}

\begin{abstract}
According to the problem-solving framework of executive functions, the first step is to construct a problem space, i.e., the representation of the problem and its possible solutions. We explored how different problem spaces affect students' proportional reasoning. Proportional reasoning is important in school and in everyday life. It involves the comparison of ratios and is known to be difficult. Previous studies have shown that difficulties in proportional reasoning may stem from the interference of the automatic comparison of the salient natural numbers that comprise the ratios. We designed two equivalent comparison of ratios tests that were visually very similar, the Drops test and the Juice test. In the Drops test, tenth graders were asked to compare the intensity of color of mixtures of red and white paint drops. In the Juice test, they were asked to compare the amount of juice each child receives when equally dividing the contents of cups of juice among children in each group. The Juice test was aimed at presenting the task in a mode leading to a problem space that directs students to calculate "rate per unit," thereby reducing the interference of the automatic comparison of the salient natural numbers. The findings indicated that success in the Juice test was higher than in the Drops test. Moreover, success in the Drops test was higher when performed after the Juice test. The current study suggests using modes of presentation that lead to problem spaces that direct students to use appropriate solution strategies, hence aiding them in overcoming difficulties. Using modes or orders of presentation could serve as important tools for educators in science and mathematics and could lead to higher academic achievements among their students.
\end{abstract}

\footnotetext{
${ }^{1}$ Tel Aviv University, The Constantiner School of Education, Department of Mathematics, Science and Technology Education, Tel Aviv, Israel

${ }^{2}$ Tel Aviv University, The Sagol School of Neuroscience, Tel Aviv, Israel

* Author email address: reuvenb@post.tau.ac.il
}

To cite this article: Babai, R., Cohen, E., \& Stavy, R. (2018). Proportional reasoning: Reducing the interference of natural numbers through an intervention based on the problem-solving framework of executive functions. Neuroeducation, 5(2), 109-118.

DOI: https://doi.org/10.24046/neuroed.20180502.109

Received on November $24^{\text {th }}$, 2017. Received in revised form on April $28^{\text {th }}, 2018$.

Accepted on May $10^{\text {th }}, 2018$. Available online on September $19^{\text {th }}, 2018$.

Neuroeducation, 5(2), 109-118

ISSN: 1929-1833

All rights reserved (C) 2018 - Association for Research in Neuroeducation 


\section{Introduction}

Executive functions play a significant role in problem solving. The problem-solving framework of executive functions identifies four temporally distinct phases (Zelazo et al., 1997): representation, planning, execution, and evaluation. The first step in solving a problem is constructing a problem space. The problem space is the representation of the problem and its possible solutions. Studies in science and mathematics education have shown that students' performance is affected by the way in which problems are presented (e.g., Clement, 1993; Elia, Gagatsis, \& Demetriou, 2007; Martin \& Schwartz, 2014; Stavy \& Berkovitz, 1980; Tirosh \& Tsamir, 1996; Tsamir, 2003).

Stavy (1991) studied conservation of matter by students, for example, using two presentation modes, showing that students correctly conserved weight when a colorful gas (iodine) was evaporated in a closed test tube but not when a colorless gas (acetone) was used (58 \% vs. $13 \%$ ). It seems that when iodine was evaporated the created problem space supported students' appropriate solution strategies. These findings raised the possibility of improving students' performance in the colorless gas (acetone) conservation of weight task by first presenting the colorful gas (iodine) conservation of weight task, which supports appropriate solution strategies. Indeed, performance in the acetone conservation of weight task was found to be significantly higher $(44 \%)$ when it followed the iodine conservation of weight task.

Performance in the comparison of perimeters task in two modes of presentation was recently explored (Babai, Nattiv, \& Stavy, 2016). In the comparison of perimeters task it was previously shown that the irrelevant salient variable area interferes with students' reasoning about the relevant variable, perimeter. In one mode of presentation, the perimeters of the geometrical shapes were drawn continuously (continuous mode of presentation). In the other mode they were drawn as built from separate units, matchsticks (discrete mode of presentation). It was found that success in the discrete mode of presentation was higher than in the continuous mode. Moreover, success in the continuous mode increased as a result of previously performing the task in the discrete mode. It was suggested that the problem space created by the discrete mode of presentation led students to appropriate solution strategies, such as moving of segments and/or counting them. The study indicated that altering the mode or order of presentation could serve as an educational tool that might improve students' performance. The current study focuses on a comparison of ratios task, known to be difficult for many students. We presented the task using two modes of presentation that lead to different problem spaces and hence to different solution strategies. We ask whether the mode of presentation affects students' performance in comparing ratios. Previous research has found that in comparison of ratios, much like in the comparison of perimeters, salient variables interfered with students' reasoning.
Proportional reasoning is the ability to compare quantities multiplicatively using ratios and numerical constructs such as fractions. It involves the use of ratios in the comparison of quantities and requires the understanding of direct and inverse relations. It is needed in many science disciplines, when calculating, for example, concentrations, probabilities, densities, velocities, and currents, and is used in mathematics for geometry and algebra. Finally, everyday life financial and purchasing decisions require its use.

Research has shown that proportional reasoning is difficult for many students and adults (e.g., Gómez et al., 2015; Inhelder \& Piaget, 1958; Karplus, Pulos, \& Stage 1983; Lamon, 2007; Moss \& Case, 1999; Ni \& Zhou, 2005; Noelting, 1980a, 1980b; Reiss et al., 1985; Siegler, 1976). The following example demonstrates a common difficulty associated with comparison of ratios. Adolescents were presented with two boxes (Box A containing 3 black balls and 1 white ball, and Box B containing 6 black balls and 2 white balls) and asked to decide if they were more likely to pick a black ball from one of the two boxes, without looking, or if the chance was equal (Green, 1983). The most common response was incorrect, Box B. According to Stavy and Tirosh (2000), this response reflects interference of the salient number of black balls, with formal/logical reasoning. The findings suggest that participants compare the number of black balls in each box instead of calculating the ratios between the number of black and white balls. Comparison of numbers is known as an automatic intuitive process (e.g., Dehaene, 2011). It should be noted that such interference of natural numbers was also observed when using symbolic notations of ratios (like fractions) in several behavioral (Bonato et al., 2007; Kallai \& Tzelgov, 2009; Meert, Grégoire, \& Noël, 2009; Vamvakoussi, Van Dooren, \& Verschaffel, 2012) and brain-imaging studies (Ischebeck, Schocke, \& Delazer, 2009; Stavy, Babai, \& Kallai, 2016).

In general, Fischbein (1987) who studied the role of intuition in science and mathematics claimed that some of students' erroneous responses could arise from intuitive reasoning. Recently, it has been suggested that students' difficulties in science and mathematics could stem from the interference of salient (intuitively, automatically processed) irrelevant variables with formal/logical reasoning (e.g., Stavy \& Babai, 2008, 2010). Apparently, certain variables of the task are so salient that they are automatically processed and thus interfere with correct reasoning.

To explore intuitive interference in comparison of ratios, a nonsymbolic reaction time comparison of probabilities task that included congruent and incongruent trials (see Figure 1) was designed (Babai et al., 2006). In congruent trials there was no intuitive interference, as one box had a larger number of black balls and a higher probability of picking a black ball. In incongruent trials there was interference, as one box had a larger number of black balls, but a lower probability of picking a black ball. 


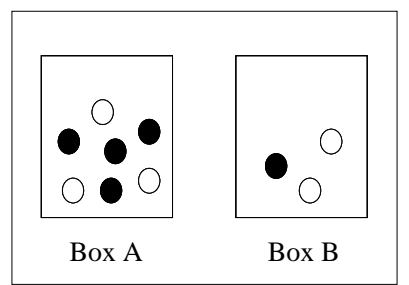

Congruent

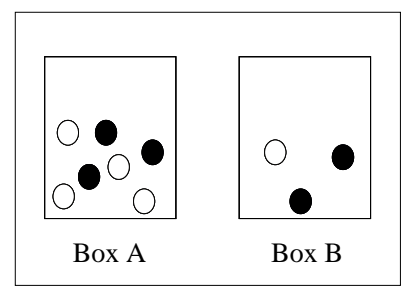

Incongruent
Figure 1. Examples of congruent and incongruent comparison of probabilities task trials

Findings showed that high school students' accuracy of responses in congruent trials was significantly higher than in incongruent ones. Reaction time of correct responses (RTC) in congruent trials was significantly shorter than in incongruent ones (Babai et al., 2006). It was suggested that when the automatic comparison of the number of black balls and that of the probability of picking a black ball resulted in the same conclusion as in congruent trials, students answered correctly and quickly. When the outcome was two different conclusions, a conflict was created. Resolving this conflict was found to be a demanding and a time-consuming process.

Recently, comparison of ratios was studied using reaction time methodology and fMRI brain-imaging (Stavy et al., 2016). Participants in this study were asked to decide which of two mixtures of red and white paint drops (presented in Arabic numerals) was darker. The findings of this study suggested that intuitive automatic comparison of natural numbers supports or suppresses the comparison of ratios as a function of congruity and salience. These findings indicated that participants attend to and compare the natural numbers that comprise the ratios, as was found in previous behavioral and brain-imaging studies dealing with fractions (e.g., Bonato et al., 2007; Ischebeck et al., 2009; Kallai \& Tzelgov, 2009; Meert et al., 2009). Stavy and her colleagues (2016) suggested that interference of the intuitive automatic comparison of natural numbers when solving comparison of ratios problems might be reduced by directing students to choose an appropriate solution strategy, for example to calculate "rate per unit" ratios. Based on the problem-solving framework of executive functions (Zelazo et al., 1997), the current study aims to explore whether creating a different problem space that directs students to calculate "rate per unit" ratios in presentation of the task would improve their performance.

For the current study we designed two equivalent comparison of ratios tests. Both tests were presented nonsymbolically and were visually very similar. In one test, the Drops test, students were asked to compare the intensity of color of mixtures of red and white paint drops, i.e., to judge whether the right mixture was darker, the left mixture was darker, or the two mixtures were equally dark (as done previously by Stavy et al., 2016). In the second test, the Juice test, students were asked to compare the amount of juice each child receives when equally dividing the contents of cups of juice among children in each group, i.e., to judge whether the amount of juice each child in the right group receives is larger, the amount of juice each child in the left group receives is larger, or the amount of juice each child in both groups receives is equal. Figure 2 depicts equivalent trials (direct ratio) as presented in the Drops and Juice tests. The comparison of ratios task, when presented in the Juice test (Figure 2A), rather than in the Drops test (Figure 2B), is likely to direct students to calculate "rate per unit," thereby reducing the interference caused by the automatic comparison of natural numbers. This may improve students' performance in comparison of ratios trial types in which there is intuitive interference.

\section{A. Drops test}

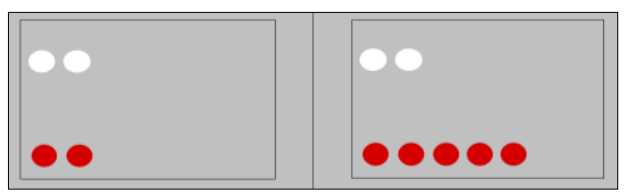

B. Juice test

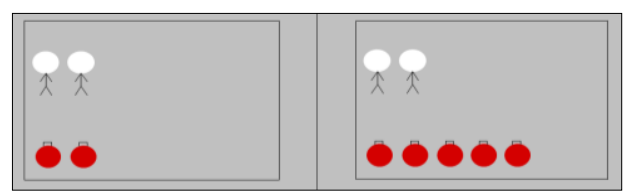

Figure 2. Equivalent comparison of ratios trials, presented in the Drops test (A) and in the Juice test (B)

It was previously suggested that both congruity and salience affect performance in comparison of ratios trials (Stavy et al., 2016). We therefore expected that the automatic comparison of natural numbers (e.g., number of red drops/juice cups) would interfere with proportional reasoning in the incongruent condition. In addition, we expect that decreasing the level of salience of the number of red drops/juice cups in the congruent condition will interfere with participants' performance in the task.

Figure 3 depicts the different trial types that were used in the current study (in the Drops test form).

With respect to congruity:

In congruent trials, in the Drops test, the mixture with the larger number of red drops is darker; in the Juice test, each child from the group that has a larger number of juice cups receives a larger amount of juice.

In incongruent trials, in the Drops test, the mixture with the larger number of red drops is equally as dark as the other; in the Juice test, each child from the group that has a larger number of juice cups receives an equal amount of juice as each child from the other group.

Comparison between congruent (Figure 3A) and incongruent (Figure 3B) trial types in each test will enable us to explore whether presenting the Juice test that directs students to calculate "rate per unit" ratios reduces the congruity effect and improves students' performance in incongruent trials. In order to explore the effect of congruity, in both congruent 
(Figure 3A) and incongruent (Figure 3B) conditions the level of salience is the same - emphasized salience (see below).

With respect to salience:

In congruent emphasized salience trials, in the Drops test, the difference in the number of red drops is larger than the difference in the number of white drops; in the Juice test, the difference in the number of juice cups is larger than the difference in the number of children.

In congruent nonemphasized salience trials, in the Drops test, the difference in the number of red drops is equal to the difference in the number of white drops; in the Juice test, the difference in the number of juice cups is equal to the difference in the number of children.

Decreasing the level of salience of the number of red drops/juice cups in the congruent condition, by making the difference between the number of red drops equal to the difference between the number of white drops (and likewise for juice cups and children) would not support the correct response and would probably interfere with participants' performance in the task.

Comparison between congruent emphasized (Figure 3A) and congruent nonemphasized (Figure $3 \mathrm{C}$ ) trial types in each test will enable us to explore whether presenting the Juice test that directs students to calculate "rate per unit" ratios reduces the salience effect and improves students' performance in the nonemphasized congruent trials. In order to explore the effect of salience, both emphasized and nonemphasized salience conditions are congruent.

It should be noted that it is irrelevant to include incongruent nonemphasized trials in our study, as answering such trials (e. g., 2 red, 2 white in Box A; 5 red, 5 white in Box B) does not actually require proportional reasoning.

The current study is based on the problem-solving framework of executive functions and on our view that students' difficulties may stem from intuitive interference of salient variables. The comparison of ratios task was presented in two modes of presentation that might lead to different problem spaces and hence direct different solution strategies. We hypothesized that a presentation mode that directed students to calculate "rate per unit" (the Juice test) would reduce the interference caused by the automatic comparison of natural numbers and result in better performance. In the current study we explored whether the Juice test would yield a higher success rate than would the Drops test among tenth graders. Moreover, following up on the recent study of Babai and his colleagues (2016), we investigated whether an intervention of previously performing the Juice test, which is visually very similar to the Drops test, would improve students' success in a subsequent Drops test.

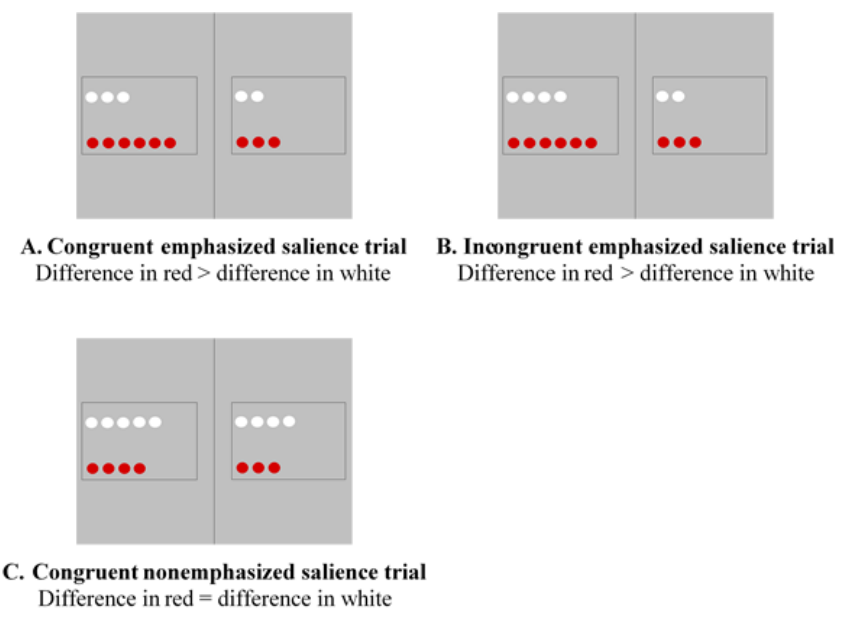

Figure 3. Examples of trial types used in the current study to explore effects of congruity (A vs. B) and salience (A vs. C) as presented in the Drops test

\section{Methodology}

\subsection{Participants}

A total of 69 tenth-grade students from one high school in central Israel were randomly assigned to the Drops and Juice tests (33 and 36 students participated in each of the tests, respectively). Students who performed the Drops test as a first test later performed the Juice test as a second test, and vice versa.

As mastering both direct and inverse ratio trial types is required for proportional reasoning, we included in the analysis students with accuracy of responses of $80 \%$ and above in both direct and inverse ratio trials in the first test. The final sample comprised 24 students who performed the Drops test as a first test (their mean accuracy for direct and inverse ratio trails was $93 \%$ and $94 \%$ respectively; mean RTC was 2530 and 3047 milliseconds respectively) and 25 students who performed the Juice test as a first test (their mean accuracy for direct and inverse ratio trails was $91 \%$ and $95 \%$ respectively; mean RTC was 2730 and 3351 milliseconds respectively).

\subsection{Comparison of ratios task-Drops test}

The computerized comparison of ratios reaction time task was presented in two modes, Drops test and Juice test, which were visually very similar (see Figure 2).

In the Drops test each trial presented two boxes on a grey background. Each box contained red and white circles representing, respectively, red and white paint drops. Participants were informed that in each box the drops of 
paint were mixed, and they were asked to compare the intensity of color in the resulting mixtures, i.e., to judge whether the right mixture was darker, the left mixture was darker, or the two mixtures were equally dark. Participants were asked to answer correctly and as rapidly as they could. Each trial was presented on the screen until the participant responded, "left mixture" by pressing the F-key, "right mixture" by pressing the J-key, or "equally dark" by pressing the space bar.

There were 30 relevant experimental trials in the test (15 pairs of ratios that were horizontally switched): 10 congruent emphasized salience, 10 incongruent emphasized salience, and 10 congruent nonemphasized salience (see Figure 3). In addition, there were 10 direct ratio and 10 inverse ratio trials (10 pairs of ratios that were horizontally switched). Success in these trials was used as a criterion to select the participants for analysis in the current study (see the Participants section). In addition, there were 30 irrelevant trials. These irrelevant trials belonged to conditions that were not analyzed as part of the current study (for example, trials that contained an equal number of red and white paint drops). The number of red and white paint drops in each mixture ranged from one to seven. The trials were presented on a computer screen in a pseudorandom order. At the start of the test, participants were presented with eight trials, different from the experimental ones, in order to familiarize them with the task and the experimental setting. Accuracy and reaction time were recorded for each response. Students who performed the Drops test as a first test later performed the Juice test.

\subsection{Comparison of ratios task-Juice test}

The Juice test was visually very similar to the Drops test (see Figure 2). Identical ratios were presented in both tests and shown in the same order. In the Juice test, students were asked to compare the amount of juice each child (depicted in white) receives when equally dividing the contents of cups of juice (depicted in red) to children in each group, i.e., to judge whether the amount of juice each child in the right group receives is larger, the amount of juice each child in the left group receives is larger, or the amount of juice each child in both groups receives is equal. As in the Drops test, in the Juice test participants were asked to answer correctly and as rapidly as they could. Each trial was presented on the screen until the participant responded, "left group" by pressing the F-key, "right group" by pressing the J-key, or "equal" by pressing the space bar. Likewise, at the start of the Juice test, participants were presented with eight trials, different from the experimental ones, in order to familiarize them with the task and the experimental setting. Accuracy and reaction time were recorded for each response. Students who performed the Juice test as a first test later performed the Drops test.

\subsection{Data analysis}

Accuracy was measured by calculating the percentages of correct responses for each participant for each test in each of the three conditions. The reaction time analysis consisted of calculating the average RTC for each participant for each test in each of the three conditions. Repeated measure General Linear Model (GLM) was carried out in SPSS software in order to detect significant differences. In Section 3.1 (effect of mode of presentation in the first test), the variables for effect of congruity were: mode of representation (Drops test and Juice test) and congruity (congruent emphasized salience and incongruent emphasized salience). For effect of salience, variables were: mode of representation (Drops test and Juice test) and salience (congruent emphasized salience and congruent nonemphasized salience). In Sections 3.2-3.3 (effect of previous mode of presentation) the variables were: previous mode of presentation (first or second test for either the Drops test or the Juice test) and either congruity (as above) or salience (as above).

\section{Results}

\subsection{Effect of mode of presentation in the first test}

We will first present the results related to the comparison of the two modes of presentation in the first test. We compared students' performance in the tests focusing on the effect of congruity (congruent vs. incongruent, both are emphasized salience trials) and salience (emphasized vs. nonemphasized salience, both are congruent trials).

Table 1 shows rate of success and RTC for the two modes of presentation, for the congruent and incongruent emphasized salience task conditions.

Table 1. Accuracy and reaction time of correct responses (RTC) in the first test of Drops $(n=24)$ and Juice $(n=25)$ for the congruent and incongruent emphasized salience trials

\begin{tabular}{|c|c|c|c|c|}
\hline \multirow[t]{2}{*}{ Congruity } & \multicolumn{2}{|c|}{$\begin{array}{l}\text { Accuracy in percent } \\
\text { (SD) }\end{array}$} & \multicolumn{2}{|c|}{$\begin{array}{l}\text { RTC in milliseconds } \\
\text { (SD) }\end{array}$} \\
\hline & Drops & Juice & Drops & Juice \\
\hline Congruent & $\begin{array}{c}87.5 \\
(15.1)\end{array}$ & $\begin{array}{l}86.8 \\
(11.1)\end{array}$ & $\begin{array}{c}2598 \\
(1224)\end{array}$ & $\begin{array}{c}4079 \\
(2140)\end{array}$ \\
\hline Incongruent & $\begin{array}{c}25.0 \\
(26.9)\end{array}$ & $\begin{array}{c}62.0 \\
(30.5)\end{array}$ & $\begin{array}{c}4567 \\
(1785)\end{array}$ & $\begin{array}{c}5049 \\
(1424)\end{array}$ \\
\hline
\end{tabular}

Analysis of success rate revealed statistically significant main effects of mode of presentation $(F=15.38, d f=47, p<.001$, partial eta squared $=0.247)$, and congruity $(F=97.15, d f=47$, $p<.001$, partial eta squared $=0.674)$. The success rate in the Juice test was higher than in the Drops test and was higher in congruent trials than in incongruent ones. In addition, a statistically significant interaction of mode of presentation $\mathrm{x}$ congruity $(F=18.12, \quad d f=47, \quad p<.001, \quad$ partial eta squared $=0.278$ ) was found. In the incongruent condition a higher success rate was found for the Juice test than for the 
Drops test (62\% vs. $25 \%$ ), while in the congruent no difference was observed (87\% vs. $88 \%)$.

Analysis of RTC included 14 participants in the Drops test and 23 participants in the Juice test. This analysis revealed statistically significant main effects of mode of presentation $(\mathrm{F}=4.62, d f=35, p=.039$, partial eta squared $=0.117)$, and congruity $(\mathrm{F}=13.64, \quad d f=35, \quad p=.001, \quad$ partial eta squared $=0.280$ ). This analysis revealed that RTC in incongruent trials was longer than that for congruent ones (4808 milliseconds vs. 3559 milliseconds) and was longer for the Juice test in comparison to the Drops test (4669 milliseconds vs. 3698 milliseconds).

Table 2 shows rate of success and RTC, for the two modes of presentation, for the emphasized and nonemphasized salience congruent task conditions.

Table 2. Accuracy and reaction time of correct responses (RTC) in the first test of Drops $(n=24)$ and Juice $(n=25)$ for the emphasized and nonemphasized salience congruent trials

\begin{tabular}{lcccc}
\hline \multirow{2}{*}{ Salience } & \multicolumn{2}{c}{$\begin{array}{c}\text { Accuracy in percent } \\
(\mathrm{SD})\end{array}$} & $\begin{array}{c}\text { RTC in milliseconds } \\
(\mathrm{SD})\end{array}$ \\
\hline & Drops & Juice & Drops & Juice \\
\cline { 2 - 5 } & 87.5 & 86.8 & 2598 & 4079 \\
Emphasized & $(15.1)$ & $(11.1)$ & $(1224)$ & $(2140)$ \\
& 38.8 & 55.6 & 5489 & 7149 \\
Nonemphasized & $(30.0)$ & $(25.8)$ & $(2685)$ & $(5583)$ \\
& & & & \\
\hline
\end{tabular}

Analysis of success rate revealed statistically significant main effect of salience $(F=92.14, d f=47, p<.001$, partial eta squared $=0.662$ ). The success rate was higher in emphasized congruent trials than in nonemphasized congruent ones. In addition, a statistically significant interaction of mode of presentation x salience $(\mathrm{F}=4.44, d f=47, p=.040$, partial eta squared $=0.086$ ) was found. In the nonemphasized congruent condition a higher success rate was found for the Juice test than for the Drops test (56 \% vs. $39 \%$ ), while in the emphasized congruent condition no difference was observed (87\% vs. $88 \%$ ).

Analysis of RTC included 20 participants in the Drops test and 24 participants in the Juice test. This analysis revealed that the effect of mode of presentation reached a significance level of $p=.075(F=3.33, d f=42$, partial eta squared $=0.074)$.

The analysis revealed a statistically significant main effect of salience $(F=22.80, \quad d f=42, \quad p<.001, \quad$ partial eta squared $=0.352$ ). This analysis revealed that RTC in nonemphasized congruent trials was longer than that for emphasized congruent ones (6319 milliseconds vs. 3424 milliseconds).
Overall, the above findings clearly indicate, as expected, that in both tests, congruity and salience affect student responses for both accuracy and RTC.

3.2 Drops test: Effect of previous mode of presentation on accuracy of responses and RTC

In this section we describe the accuracy and RTC of the Drops test administered as a first test to one group of students, and as a second test, administered after the Juice test, to a second group of students. The findings for congruent and incongruent emphasized salience trials are depicted in Table 3.

Table 3. Accuracy and reaction time of correct responses (RTC) in the Drops test presented as a first test to one group $(n=24)$ and as a second test to another group after performing the Juice test $(n=25)$ for the congruent and incongruent emphasized salience trials

\begin{tabular}{lcccc}
\hline \multirow{2}{*}{ Congruity } & \multicolumn{2}{c}{$\begin{array}{c}\text { Accuracy in percent } \\
\text { (SD) }\end{array}$} & \multicolumn{2}{c}{$\begin{array}{c}\text { RTC in milliseconds } \\
\text { (SD) }\end{array}$} \\
\hline \multirow{4}{*}{ Congruent } & $\begin{array}{c}\text { Drops as } \\
\text { first }\end{array}$ & $\begin{array}{c}\text { Drops } \\
\text { after Juice }\end{array}$ & $\begin{array}{c}\text { Drops as } \\
\text { first }\end{array}$ & $\begin{array}{c}\text { Drops } \\
\text { after Juice }\end{array}$ \\
\cline { 2 - 5 } & 87.5 & 87.2 & 2598 & 2731 \\
Incongruent & $(15.1)$ & $(15.4)$ & $(1224)$ & $(1255)$ \\
& 25.0 & 52.0 & 4567 & 4164 \\
& $(26.9)$ & $(32.2)$ & $(1785)$ & $(1426)$ \\
\hline
\end{tabular}

Analysis revealed statistically significant main effects of previous mode of presentation $(F=8.29, d f=47, p=.006$, partial eta squared $=0.150)$ and congruity $(F=98.85, d f=47$, $p<.001$, partial eta squared $=0.678)$. Success rate in the Drops test when following the Juice test was higher than that of Drops test as a first test (70 \% vs. $56 \%$, respectively) and is significantly higher in congruent than in incongruent trials ( $87 \%$ vs. $39 \%$, respectively). A statistically significant interaction of previous mode of presentation $\mathrm{x}$ congruity $(F=7.72, d f=47, p=.008$, partial eta squared $=0.141)$ was found. The improvement in success rate was only evident in incongruent trials (from $25 \%$ to $52 \%$ ).

Analysis of RTC included 14 participants in the Drops test as a first test and 24 participants in the drops test as a second test. This analysis revealed no statistically significant effects related to previous presentation mode; only main effect of congruity was observed $(\mathrm{F}=31.58, d f=36, p<.001$, partial eta squared $=0.467)$. RTC for incongruent trials was longer than that for congruent ones (4365 milliseconds vs. 2804 milliseconds).

The findings for emphasized and nonemphasized salience congruent trials of the Drops test administered as a first test to one group of students, and as a second test, administered after the Juice test, to a second group of students are depicted in Table 4. 
Table 4. Accuracy and reaction time of correct responses (RTC) in the Drops test presented as a first test to one group $(n=24)$ and as a second test to another group after performing the Juice test $(n=25)$ for the emphasized and nonemphasized salience congruent trials

\begin{tabular}{lcccc}
\hline Salience & \multicolumn{2}{c}{$\begin{array}{c}\text { Accuracy in percent } \\
\text { (SD) }\end{array}$} & $\begin{array}{c}\text { RTC in milliseconds } \\
(\mathrm{SD})\end{array}$ \\
\hline \multirow{4}{*}{ Emphasized } & $\begin{array}{c}\text { Drops as } \\
\text { first }\end{array}$ & $\begin{array}{c}\text { Drops } \\
\text { after Juice }\end{array}$ & $\begin{array}{c}\text { Drops as } \\
\text { first }\end{array}$ & $\begin{array}{c}\text { Drops } \\
\text { after Juice }\end{array}$ \\
\cline { 2 - 5 } & 87.5 & 87.2 & 2598 & 2731 \\
& $(15.1)$ & $(15.4)$ & $(1224)$ & $(1255)$ \\
Nonemphasized & 38.8 & 67.6 & 5489 & 4135 \\
& $(30.0)$ & $(23.9)$ & $(2685)$ & $(2002)$ \\
\hline
\end{tabular}

Analysis revealed statistically significant main effects of previous mode of presentation $(\mathrm{F}=9.09, d f=47, p=.004$, partial eta squared $=0.162)$ and salience $(F=69.01, d f=47$, $p<.001$, partial eta squared $=0.595$ ). Success rate in the Drops test when following the Juice test was higher than that in the Drops test as a first test (77\% vs. $63 \%$, respectively) and was significantly higher in emphasized than in nonemphasized congruent trials ( $87 \%$ vs. $53 \%$, respectively). A statistically significant interaction of previous mode of presentation x salience $(\mathrm{F}=12.55, d f=47, p=.001$, partial eta squared $=0.211$ ) was found. The improvement in success rate was only evident in nonemphasized congruent trials (from $39 \%$ to $68 \%$ ).

Analysis of RTC included 20 participants in the Drops test as a first test and 25 participants in the Drops test as a second test. This analysis revealed statistically significant main effect of salience $(F=53.78, \quad d f=43, \quad p<.001$, partial eta squared $=0.556$ ). RTC for nonemphasized trials was longer than that for emphasized congruent ones (4812 milliseconds vs. 2720 milliseconds). In addition, a statistically significant interaction of previous mode of presentation $\mathrm{x}$ salience $(F=5.80, d f=43, p=.020$, partial eta squared $=0.119)$ was found. RTC in nonemphasized trials was reduced from first to second test (5489 milliseconds vs. 4135 milliseconds), while no difference was observed for emphasized ones (2710 milliseconds vs. 2731 milliseconds).

\subsection{Juice test: Effect of previous mode of presentation on} accuracy of responses and RTC

In this section we describe the accuracy and RTC for the Juice test administered as a first test to one group of students, and as a second test, administered after the Drops test, to a second group of students. The findings for congruent and incongruent emphasized salience trials are depicted in Table 5.
Table 5. Accuracy and reaction time of correct responses (RTC) in the Juice test presented as a first test to one group $(n=25)$ and as a second test to another group after performing the Drops test $(n=24)$ for the congruent and incongruent emphasized salience trials

\begin{tabular}{lcccc}
\hline \multirow{2}{*}{ Congruity } & \multicolumn{2}{c}{$\begin{array}{c}\text { Accuracy in percent } \\
\text { (SD) }\end{array}$} & \multicolumn{2}{c}{$\begin{array}{c}\text { RTC in milliseconds } \\
\text { (SD) }\end{array}$} \\
\hline \multirow{4}{*}{ Congruent } & $\begin{array}{c}\text { Juice as } \\
\text { first }\end{array}$ & $\begin{array}{c}\text { Juice after } \\
\text { Drops }\end{array}$ & $\begin{array}{c}\text { Juice as } \\
\text { first }\end{array}$ & $\begin{array}{c}\text { Juice after } \\
\text { Drops }\end{array}$ \\
\cline { 2 - 5 } & 86.8 & 86.3 & 4079 & 3444 \\
& $(11.1)$ & $(15.6)$ & $(2140)$ & $(2077)$ \\
Incongruent & 62.0 & 45.1 & 5049 & 4728 \\
& $(30.5)$ & $(30.6)$ & $(1424)$ & $(2208)$ \\
\hline
\end{tabular}

Analysis of accuracy of responses revealed no statistically significant effects related to previous presentation mode; only main effect of congruity was observed $(F=49.82, d f=47$, $p<.001$, partial eta squared $=0.515$ ). Success rate is significantly higher in congruent than in incongruent trials ( $87 \%$ vs. $54 \%$, respectively). In contrast to the Drops test, in the Juice test (as a second test) no improvement in accuracy was evident in incongruent trials performed after the Drops test.

Analysis of RTC included 23 participants in the Juice test as a first test and 19 participants in the Juice test as a second test. This analysis revealed no statistically significant effects related to previous presentation mode; only main effect of congruity was observed $(F=7.31, d f=40, p=.010$, partial eta squared $=0.155)$. RTC for incongruent trials was longer than that for congruent ones (4889 milliseconds vs. 4052 milliseconds).

The findings for emphasized and nonemphasized salience congruent trials of the Juice test administered as a first test to one group of students, and as a second test, administered after the Drops test, to a second group of students are depicted in Table 6.

Table 6. Accuracy and reaction time of correct responses (RTC) in the Juice test presented as a first test to one group $(n=25)$ and as a second test to another group after performing the Drops test $(n=24)$ for the emphasized and nonemphasized salience congruent trials

\begin{tabular}{lcccc}
\hline \multirow{2}{*}{ Salience } & \multicolumn{2}{c}{$\begin{array}{c}\text { Accuracy in percent } \\
(\mathrm{SD})\end{array}$} & $\begin{array}{c}\text { RTC in milliseconds } \\
(\mathrm{SD})\end{array}$ \\
\hline \multirow{4}{*}{ Emphasized } & $\begin{array}{c}\text { Juice as } \\
\text { first }\end{array}$ & $\begin{array}{c}\text { Juice after } \\
\text { Drops }\end{array}$ & $\begin{array}{c}\text { Juice as } \\
\text { first }\end{array}$ & $\begin{array}{c}\text { Juice after } \\
\text { Drops }\end{array}$ \\
\cline { 2 - 5 } & 86.8 & 86.3 & 4079 & 3444 \\
& $(11.1)$ & $(15.6)$ & $(2140)$ & $(2077)$ \\
Nonemphasized & 55.6 & 45.8 & 7149 & 6582 \\
& $(25.8)$ & $(23.8)$ & $(5583)$ & $(4845)$ \\
\hline
\end{tabular}


Analysis of accuracy of responses revealed no statistically significant effects related to previous presentation mode; only main effect of salience was observed $(F=80.30, d f=47$, $p<.001$, partial eta squared $=0.631$ ). Success rate was significantly higher in emphasized than in nonemphasized congruent trials ( $87 \%$ vs. $51 \%$, respectively). In contrast to the Drops test, in the Juice test (as a second test) no improvement in accuracy was evident in nonemphasized salient trials performed after the Drops test.

Analysis of RTC included 24 participants in the Juice test as a first test and 12 participants in the Juice test as a second test. This analysis revealed no statistically significant effects related to previous presentation mode; only main effect of salience was observed $(F=17.19, d f=44, p<.001$, partial eta squared $=0.281$ ). RTC for nonemphasized trials was longer than that for emphasized ones (6866 milliseconds vs. 3866 milliseconds).

\section{Discussion}

The current study is based on the problem-solving framework of executive function, specifically on the first step of constructing a problem space (Zelazo et al., 1997). The problem space is the representation of the problem and its possible solutions. Therefore, a different problem space could be constructed when presenting a problem in a different mode. Choosing a specific mode of presentation may lead to construction of a different problem space that might suggest appropriate solution strategies and thus help solvers in overcoming difficulties. Our study illustrates how executive functions are involved in problem solving related to proportional reasoning.

Proportional reasoning, an important skill in school and in daily life, is known to be difficult for schoolchildren and adults (e.g., Karplus et al., 1983). We focused here on a comparison of ratios task known to be difficult for many students due to the interference of the automatic comparison of the salient natural numbers that comprise the ratios. Such interference was previously reported based on behavioral and fMRI brainimaging studies (e.g., Ischebeck et al., 2009; Kallai \& Tzelgov, 2009; Meert et al., 2009; Stavy et al., 2016). Based on the problem-solving framework of executive functions we expected that using two different presentations of the comparison of ratios task would lead to different solution strategies. We designed two nonsymbolically equivalent comparison of ratios tasks that were visually very similar, the Drops test and the Juice test. The Juice test (Figure 2A), in comparison to the Drops test (Figure 2B), was aimed at creating a problem space that directed students to calculate "rate per unit," thereby reducing the interference of the automatic comparison of the salient natural numbers.

We studied here whether the Juice test would yield a higher success rate than would the Drops test among tenth graders. We also explored whether performing the Juice test before the Drops test would improve students' success in the Drops test. Findings of the current study indicate that, indeed, success in the Juice test is higher than in the Drops test, for both incongruent emphasized salience and congruent nonemphasized salience trials. Moreover, success in these conditions in the Drops test is higher when performed after the Juice test. Below we discuss our findings related to the effect of mode of presentation in the first test and the effect of previous presentation mode.

\subsection{Effect of mode of presentation in the first test}

Previous studies in science and mathematics education have suggested that specific modes of presentation improve students' performance (e.g., Clement, 1993; Elia et al., 2007; Martin \& Schwartz, 2014; Tirosh \& Tsamir, 1996; Tsamir, 2003). Findings of the current study clearly show that success rate in the Juice test is significantly higher than in the Drops test for trials in which interference caused by the automatic comparison of natural numbers is evident, i.e., incongruent emphasized trials and congruent nonemphasized ones. The Juice test probably leads to a problem space that directs students to apply more complex, time consuming, appropriate strategies, such as calculation of per unit ratios (i.e., dividing juice from cups among groups of children). In the Drops test, however, no hints to such strategies of calculating per unit ratios are given and students who rely on the salient numbers of drops tend to provide more incorrect responses. The findings suggest that the Juice test results in an overall longer RTC (for the salience effect, statistical significance level is $p=.075$ ), indicating that the solution strategies for the Juice test are more complex.

It should be noted that although performance is much higher in the Juice test, effects of both congruity and salience are still evident, indicating that intuitive interference continues to affect students' reasoning even when their performance is improved.

\subsection{Effect of previous presentation mode}

Success rate for the Juice test was higher than for the Drops test when each was presented as a first test. Comparing the Drops test before and after performing the Juice test indicated that students' success rate in the Drops test is higher after performing the Juice test, while students' success rate in the Juice test is not higher when performed after the Drops test.

These findings suggest that the problem space constructed in the Juice test is later used when performing the Drops test. This transfer probably stems from the visual similarity between the two tests. Further studies are needed in order to explore the importance of visual similarity for transfer of appropriate solution strategies.

\section{Conclusions}

The current study provides some practical implications for education. For example, educators could consider using modes of presentations that lead to problem spaces that would direct students to use appropriate solution strategies 
that will aid them in overcoming difficulties. Using modes or orders of presentation could serve as important tools for educators of science and mathematics and could lead to higher academic achievements of students in science and mathematics.

The positive effect of a previous presentation mode observed in the current study can be seen as "teaching by analogy." In teaching by analogy students are first presented with an "anchoring task" that elicits a correct response due to the way it is presented, thus supporting appropriate solution strategies. Later on, students are presented with a similar "target task" known to elicit incorrect responses. The anchoring task probably encourages appropriate solution strategies, and such a sequence of instruction is effective in helping students overcome difficulties (e.g., Babai et al., 2016; Clement, 1993; Stavy, 1991; Tsamir, 2003). Further exploration through brain imaging of the brain correlates of such an intervention and studying long-term effects and possible behavioral effects in different populations (e.g., different ages, various mathematical competencies) would be beneficial.

\section{Acknowledgments}

This research was supported by the Israel Science Foundation [grant no. 464/07].

\section{References}

Babai, R., Brecher, T., Stavy R., \& Tirosh, D. (2006). Intuitive interference in probabilistic reasoning. International Journal of Science and Mathematics Education, 4(4), 627639. https://doi.org/10.1007/s10763-006-9031-1

Babai, R., Nattiv, L., \& Stavy, R. (2016). Comparison of perimeters: Improving students' performance by increasing the salience of the relevant variable. ZDM Mathematics Education, 48(3), 367-378.

https://doi.org/10.1007/s11858-016-0766-z

Bonato, M., Fabbri, S., Umiltà, C., \& Zorzi, M. (2007). The mental representation of numerical fractions: Real or integer? Journal of Experimental Psychology: Human Perception and Performance, 33(6), 1410-1419. https://doi.org/10.1037/0096-1523.33.6.1410

Clement, J. (1993). Using bridging analogies and anchoring intuitions to deal with students' preconceptions about physics. Journal of Research in Science Teaching, 30(10), 1241-1257. https://doi.org/10.1002/tea.3660301007

Dehaene, S. (2011). The number sense: How the mind creates mathematics, revised and updated edition. New York, NY: Oxford University Press.

Elia, I., Gagatsis, A., \& Demetriou, A. (2007). The effects of different modes of representation on the solution of onestep additive problems. Learning and Instruction, 17(6), 658-672. https://doi.org/10.1016/j.learninstruc.2007.09.011
Fischbein, E. (1987). Intuition in science and mathematics. Dordrecht, The Netherlands: Reidel.

Gómez, D. M., Jiménez, A., Bobadilla, R., Reyes, C., \& Dartnell, P. (2015). The effect of inhibitory control on general mathematics achievement and fraction comparison in middle school children. ZDM Mathematics Education, 47(5), 801-811. https://doi.org/10.1007/s11858-0150685-4

Green, D. R. (1983). A survey of probabilistic concepts in 3000 students aged 11-16 years. In D. R. Grey, P. Holmes, V. Barnett, \& G. M. Constable (Eds.), Proceedings of the First International Conference on Teaching Statistics (pp. 766783). Sheffield, UK: Teaching Statistics Trust.

Inhelder, B., \& Piaget, J. (1958). The growth of logical thinking: From childhood to adolescence. New York, NY: Basic Books.

Ischebeck, A., Schocke, M., \& Delazer, M. (2009). The processing and representation of fractions within the brain: An fMRI investigation. NeuroImage, 47(1), 403-413. https://doi.org/10.1016/j.neuroimage.2009.03.041

Kallai, A. Y., \& Tzelgov, J. (2009). A generalized fraction: An entity smaller than one on the mental number line. Journal of Experimental Psychology: Human Perception and Performance, 35(6), 1845-1864. https://doi.org/10.1037/a0016892

Karplus, E., Pulos, S., \& Stage, E. K. (1983). Proportional reasoning of early adolescents. In R. Lesh \& M. Landau (Eds.), Acquisition of mathematics concepts and processes (pp. 45-90). New York, NY: Academic Press.

Lamon, S. J. (2007). Rational numbers and proportional reasoning: Toward a theoretical framework for research. In F. Lester (Ed.), Second handbook of research on mathematics teaching and learning (pp. 629-668). Reston, VA: NCTM.

Martin, L., \& Schwartz, D. L. (2014). A pragmatic perspective on visual representation and creative thinking. Visual Studies, 29(1), 80-93. https://doi.org/10.1080/1472586x.2014.862997

Meert, G., Grégoire, J., \& Noël, M.-P. (2009). Rational numbers: Componential versus holistic representation of fractions in a magnitude comparison task. Quarterly Journal of Experimental Psychology, 62(8), 1598-1616 https://doi.org/10.1080/17470210802511162

Moss, J., \& Case, R. (1999). Developing children's understanding of the rational numbers: A new model and an experimental curriculum. Journal for Research in Mathematics Education, 30(2), 122-147. https://doi.org/10.2307/749607

Ni, Y., \& Zhou, Y. D. (2005). Teaching and learning fraction and rational numbers: The origins and implications of whole number bias. Educational Psychologist, 40(1), 27-52. https://doi.org/10.1207/s15326985ep4001_3 
Noelting, G. (1980a). The development of proportional reasoning and the ratio concept (the Orange Juice Experiment), Part 1: The determination of stages. Educational Studies in Mathematics, 11(2), 217-253. https://doi.org/10.1007/bf00304357

Noelting, G. (1980b). The development of proportional reasoning and the ratio concept, Part 2: Problem structure at successive stages; problem-solving strategies and the mechanism of adaptive restructuring. Educational Studies in Mathematics, 11(3), 331-363. https://doi.org/10.1007/bf00697744

Reiss, M., Behr, M., Lesh, R., \& Post, T. (1985). Cognitive processes and products in proportional reasoning. In $\mathrm{L}$. Streefland (Ed.), Proceedings of the Ninth International Conference for the Psychology of Mathematics Education (pp. 352-356). Noordwijkerhout (Utrecht), Netherlands: PME.

Siegler, R. S. (1976). Three aspects of cognitive development. Cognitive Psychology, 8(4), 481-520. https://doi.org/10.1016/0010-0285(76)90016-5

Stavy, R. (1991). Using analogy to overcome misconceptions about conservation of matter. Journal of Research in Science Teaching, 28(4), 305-313. https://doi.org/10.1002/tea.3660280404

Stavy, R., \& Babai, R. (2010). Overcoming intuitive interference in mathematics: Insights from behavioral, brain imaging and intervention studies. ZDM Mathematics Education, 42(6), 621-633. https://doi.org/10.1007/s11858-010-0251-z

Stavy, R., \& Babai, R. (2008). Complexity of shapes and quantitative reasoning in geometry. Mind, Brain, and Education, 2(4), 170-176. https://doi.org/10.1111/j.1751228x.2008.00051.x
Stavy, R., Babai, R., \& Kallai, A. Y. (2016). Proportional reasoning: The role of congruity and salience in behavioral and imaging research. Zeitschrift für Psychologie, 224(4), 266-276. https://doi.org/10.1027/2151-2604/a000262

Stavy, R., \& Berkovitz, B. (1980). Cognitive conflict as a basis for teaching quantitative aspects of the concept of temperature. Science Education, 64(5), 679-692. https://doi.org/10.1002/sce.3730640514

Stavy, R., \& Tirosh, D. (2000). How students (mis-)understand mathematics and science. New York, NY: Teachers College Press.

Tirosh, D., \& Tsamir, P. (1996). The role of representations in students' intuitive thinking about infinity. International Journal of Mathematical Education in Science and Technology, 27(1), 33-40. https://doi.org/10.1080/0020739960270105

Tsamir, P. (2003). From "easy" to "difficult" or vice versa: The case of infinite sets. Focus on Learning Problems in Mathematics, 25(2), 1-17.

Vamvakoussi, X., Van Dooren, W., \& Verschaffel, L. (2012). Naturally biased? In search for reaction time evidence for a natural number bias in adults. The Journal of Mathematical Behavior, 31(3), 344-355. https://doi.org/10.1016/j.jmathb.2012.02.001

Zelazo, P. D., Carter, A., Reznick, J. S., \& Frye, D. (1997). Early development of executive function: A problem-solving framework. Review of General Psychology, 1(2), 198-226. https://doi.org/10.1037/1089-2680.1.2.198 